\title{
Nanofibrillated cellulose composite hydrogel for the replacement of the nucleus pulposus
}

\author{
Ana C. Borges ${ }^{a}$, Christian Eyholzer ${ }^{\mathrm{b}, \mathrm{d}}$, Fabien Duc ${ }^{\mathrm{a}}$, Pierre-Etienne Bourban ${ }^{\mathrm{a}, *}$, Philippe Tingaut ${ }^{\mathrm{b}}$, \\ Tanja Zimmermann ${ }^{\mathrm{b}}$, Dominique P. Pioletti ${ }^{\mathrm{c}}$, Jan-Anders E. Månson ${ }^{\mathrm{a}}$ \\ a Laboratoire de Technologie des Composites et Polymères (LTC), Ecole Polytechnique Fédérale de Lausanne (EPFL), Station 12, CH-1015 Lausanne, Switzerland \\ ${ }^{\mathrm{b}}$ Wood Laboratory, Swiss Federal Laboratories for Materials Testing and Research (EMPA), Ueberlandstrasse 129, CH-8600 Duebendorf, Switzerland \\ ${ }^{\mathrm{c}}$ Laboratoire de Biomécanique en Orthopédie (LBO), Ecole Polytechnique Fédérale de Lausanne (EPFL), Station 11, CH-1015 Lausanne, Switzerland \\ ${ }^{\mathrm{d}}$ Division of Manufacturing and Design of Wood and Bionanocomposites, Luleå University of Technology (LTU), Luleå, Sweden
}

\section{A R T I C L E I N F O}

\section{Article history:}

Received 16 December 2010

Received in revised form 9 May 2011

Accepted 20 May 2011

Available online 27 May 2011

\section{Keywords:}

Composite hydrogel

Nucleus pulposus

Compression and shear properties

Swelling behavior

Nanofibrillated cellulose

\begin{abstract}
A B S T R A C T
The swelling and compressive mechanical behavior as well as the morphology and biocompatibility of composite hydrogels based on Tween ${ }^{\circledR} 20$ trimethacrylate (T3), N-vinyl-2-pyrrolidone (NVP) and nanofibrillated cellulose (NFC) were assessed in the present study. The chemical structure of T3 was verified by Fourier transform infrared spectroscopy and proton nuclear magnetic resonance, and the degree of substitution was found to be around 3. Swelling ratios of neat hydrogels composed of different concentrations of T3 and NVP were found to range from 1.5 to 5.7 with decreasing concentration of T3. Various concentrations of cellulose nanofibrils (0.2-1.6 wt.\%) were then used to produce composite hydrogels that showed lower swelling ratios than neat ones for a given T3 concentration. Neat and composite hydrogels exhibited a typical nonlinear response under compression. All composite hydrogels showed an increase in elastic modulus compared to neat hydrogel of about 3- to 8 -fold, reaching $18 \mathrm{kPa}$ at $0 \%$ strain and $62 \mathrm{kPa}$ at $20 \%$ strain for the hydrogel with the highest NFC content. All hydrogels presented a porous and homogeneous structure, with interconnected pore cells of around $100 \mathrm{~nm}$ in diameter. The hydrogels are biocompatible. The results of this study demonstrate that composite hydrogels reinforced with NFC may be viable as nucleus pulposus implants due to their adequate swelling ratio, which may restore the annulus fibrosus loading, and their increased mechanical properties, which could possibly restore the height of the intervertebral discs.
\end{abstract}

(ㄷ) 2011 Acta Materialia Inc. Published by Elsevier Ltd. All rights reserved.

\section{Introduction}

Lower back pain is mostly due to intervertebral disc (IVD) degeneration, in particular nucleus pulposus (NP) degeneration [1]. About $80 \%$ of the world population will suffer from back pain in their lifetime [2,3], and in $75 \%$ of cases this will be a direct consequence of degenerative processes of the disc. This huge public health issue now costs several billion dollars worldwide, and it is the primary cause of working days lost [3]. In the normal healthy disc, the hydrated NP exerts a hydrostatic pressure on the annulus fibrosus (AF) [4]. This pressure increases with the loads applied to the NP and causes water from the NP to be released. With recumbency, the pressure decreases and water returns, driven by osmotic pressure [5]. This creates a pump effect responsible for the mechanical properties (elastic modulus $3-6 \mathrm{kPa}$ ) of the NP [6] and for the load transfer through the AF. However, this load trans-

\footnotetext{
* Corresponding author. Tel.: +412169358 06; fax: +412169358 80 .

E-mail address: pierre-etienne.bourban@epfl.ch (P.-E. Bourban).
}

fer mechanism is altered in degenerated discs: the water content in degenerated NPs is considerably reduced, resulting in a decrease in the hydrostatic pressure [7].

Total disc arthroplasty [8,9] and NP replacement are two nonfusion techniques that have emerged as solutions to this issue. The ideal benefits of a non-fusion solution are the removal of the source of pain and the preservation of the biomechanical balance and motion of the spine $[8,9]$. Having a functional NP will then restore the biomechanics of the AF.

NP replacement with a synthetic material or with a tissue-engineered scaffold $[10,11]$ targets earlier stages of disc degeneration, when the AF is not yet affected [12]. A classical approach to replacing the NP involves mimicking the structure and function of the native NP. The NP has been described as a gel-like structure containing randomly disposed collagen fibers and radial elastin fibers [13]. The NP is inextensible, extremely deformable and very hydrophilic [14]. The mechanical properties in compression and the viscoelastic properties in shear have been previously reported $[15,16]$. While the mechanical requirements, i.e. a Young's modulus of 3$6 \mathrm{kPa}$, for an NP replacement material have been described [17], 
a standard test procedure for determining these requirements is yet to be agreed on by the regulatory and scientific communities [18].

Hydrogels are suitable materials for NP replacement due to their hydrophilic character and potential biocompatibility [19]. However, their main use has been in applications where mechanical performance is not decisive, such as contact lenses and drug delivery [20]. For the particular NP application, it is believed that a non-degradable hydrogel would be safer to use as the metabolism of the NP is very slow due to its low cell density - so the likelihood of a biodegradable hydrogel being replaced by native tissue would be extremely low. A non-degradable hydrogel could thus be developed to replace the NP; in this sense, the hydrogel is considered as a permanent implant.

Composite hydrogels have been evaluated in this study as potential candidates for the replacement of the NP. In this respect, a hydrogel reinforced with natural biocompatible nanofibers seems the best choice for mimicking the human NP. The increase in mechanical properties due to these nanofibers should not decrease the swelling ability of the hydrogel. In this context, the fibers should possess a high water retention value (WRV), which is the case for nanofibrillated cellulose (NFC). NFC is usually obtained after the mechanical disintegration of cellulose raw materials obtained from various lignocellulosic fiber sources like wood [21]. After the treatment, NFC builds up a web-like structure and shows fiber diameters from 10 to $100 \mathrm{~nm}$ [22]. Due to its large surface area, NFC has a high WRV of up to $400 \%$ [21]. NFC has already been used as reinforcement in several applications [23-25]. It has been used in polymer matrices, such as polyvinyl alcohol and hydroxypropyl cellulose, in which significant increases in Young's modulus and tensile strength were observed by Zimmermann et al. [26].

The objectives of this study were, first, to synthesize a suitable branched molecule, Tween ${ }^{\circledR} 20$ trimethacrylate (T3), and then to combine it with a monomer to obtain a highly swelling and hydrophilic co-polymer curable by ultraviolet (UV) light. In a second step, this crosslinked hydrogel was reinforced with NFC and the swelling, compression and shear properties were determined and compared to the human NP. Scanning electron microscopy (SEM) imaging and biocompatibility studies were performed on the hydrogels and finally, from the obtained results, the best candidate material for the NP replacement was determined. The direct injection of this unique gel into the cavity of the degraded native nucleus without damaging the annulus, the further UV curing and the tailored swelling of the designed composite hydrogel polymer are all part of a novel surgical approach.

\section{Materials and methods}

\subsection{Materials}

Cell-culture-tested Tween ${ }^{\circledR} 20\left(1226 \mathrm{~g} \mathrm{~mol}^{-1}\right)$ was purchased from Sigma-Aldrich (Buchs, Switzerland), dried by azeotropic distillation with benzene and stored in a desiccator. Methacryloyl

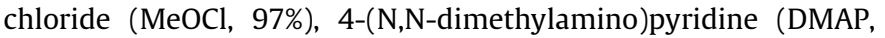
99\%) and N-vinyl-2-pyrrolidone (NVP, $111.14 \mathrm{~g} \mathrm{~mol}^{-1}$ ) were obtained from Sigma-Aldrich and used as received. Tetrahydrofuran (THF, extra dry, $<50$ ppm water) was purchased from Acros Organic (Geel, Belgium). The photoinitiator Irgacure 2959, 4-(2-hydroxyethoxy) phenyl-(2-hydroxy-2-propyl) ketone (I2959), was obtained from Ciba Specialty Chemicals (Basel, Switzerland) and used as received. For the biocompatibility studies, Giemsa's azur eosin methylene blue solution was purchased from Merck (Zug, Switzerland).

NFC from refined bleached beech pulp was obtained from the Swiss Federal Laboratories for Materials Testing and Research
(EMPA) (Duebendorf, Switzerland) as a $8 \mathrm{wt}$.\% water suspension. The NFC suspension was then diluted in deionized water to yield a concentration of $2 \mathrm{wt}$ \% of fibrils, using an ultra-turrax IKA T25 digital, SN 25 10G high shear mixer (IKA, Staufen, Germany).

\subsection{Synthesis of $\mathrm{T3}$}

Tween ${ }^{\circledR} 20(20 \mathrm{~g}, 0.016 \mathrm{~mol})$ was dissolved in $100 \mathrm{ml}$ of THF in a $250 \mathrm{ml}$ round-bottom flask, to which $6.2 \mathrm{~g}(0.06 \mathrm{~mol})$ of DMAP was introduced under argon. After cooling to $0^{\circ} \mathrm{C}$ in ice, $4.9 \mathrm{ml}$ of MeO$\mathrm{Cl}(0.049 \mathrm{~mol})$ in $30 \mathrm{ml}$ THF was added dropwise to the mixture over $30 \mathrm{~min}$ under stirring using a pressure-equalized addition funnel. The flask was covered with aluminum foil and left under stirring overnight. The resulting precipitate was then filtered off, washed with THF and dried in a rotary evaporator at room temperature, avoiding light exposure. Part of the crude product ( $3 \mathrm{~g}$ ) was purified by column chromatography (60 g of silica, eluant $\mathrm{CHCl}_{3} /$ $\mathrm{MeOH}, 9 / 1-8 / 2, \mathrm{v} / \mathrm{v}$ ), yielding $2.2 \mathrm{~g}$ of a light yellow viscous liquid after evaporation of the solvent. The T3 yield obtained after purification was 75\%. The degree of substitution (DS; the average number of substituted $\mathrm{OH}$ groups per molecule of Tween ${ }^{\circledR} 20$ ) was confirmed by Fourier transform infrared spectroscopy (FTIR; Perkin-Elmer Spectrum One, Spectrum Spotlight 300) and by proton nuclear magnetic resonance $\left({ }^{1} \mathrm{H}\right.$ NMR; Brucker Avance $400 \mathrm{MHz}$ ) with $\mathrm{CDCl}_{3}$ as the solvent.

\subsection{Neat and composite hydrogel preparation}

Hydrogels were fabricated by the photopolymerization of precursor solutions in a cylindrical silicone mould $(10 \mathrm{~mm}$ diameter and $5 \mathrm{~mm}$ deep). The precursor solutions were prepared with different concentrations of T3, NVP and photoinitiator in water to produce several hydrogels, as presented in Table 1.

The photoinitiator was used as an aqueous solution of $0.05 \mathrm{wt} . \%$ of I2959 in water, the final concentration of photoinitiator solution into the precursor solution being varied. To produce neat hydrogels, the solution was vigorously stirred at room temperature and then injected into the mould and exposed to UV light provided by an EXFO Omnicure S2000 source (270-370 nm). The UV intensity was $145 \mathrm{~mW} \mathrm{~cm}^{-2}$, and was measured using a radiometer (Solatell, UK). The UV intensity varied by less than $10 \%$ across illuminations.

Composite hydrogels were produced with the precursor solutions containing T3, NVP, I2959 and NFC ( 2 wt.\% water suspension). The final concentration of fibrils was varied and the detailed compositions are shown in Table 1 . The solutions were mixed with a high shear mixer to ensure good dispersion of the fi-

Table 1

Composition of tested hydrogels.

\begin{tabular}{lcllll}
\hline & $\begin{array}{l}\text { T3 } \\
\text { (vol.\%) }\end{array}$ & $\begin{array}{l}\text { NVP } \\
\text { (vol.\%) }\end{array}$ & $\begin{array}{l}\text { I2959 sol. } \\
\text { (vol.\%) }\end{array}$ & $\begin{array}{l}\text { Water } \\
\text { (vol.\%) }\end{array}$ & $\begin{array}{l}\text { NFC } \\
\text { (wt.\%) }\end{array}$ \\
\hline T3-4.5 & 4.5 & 45.5 & 10 & 40 & - \\
T3-8 & 8 & 42 & 10 & 40 & - \\
T3-11.5 & 11.5 & 38.5 & 10 & 40 & - \\
T3-15 & 15 & 35 & 10 & 40 & - \\
T3-8_30init & 8 & 42 & 30 & 40 & - \\
T3-8_50init & 8 & 42 & 50 & 40 & - \\
T3-8_0.4nfc & 8 & 42 & 10 & 40 & 0.4 \\
T3-8_0.8nfc & 8 & 42 & 10 & 40 & 0.8 \\
T3-15_0.4nfc & 15 & 35 & 10 & 40 & 0.4 \\
T3-15_0.8nfc & 15 & 35 & 10 & 40 & 0.8 \\
T3-4.5_0.2nfc & 4.5 & 45.5 & 10 & 40 & 0.2 \\
T3-4.5_0.4nfc & 4.5 & 45.5 & 10 & 40 & 0.4 \\
T3-4.5_0.8nfc & 4.5 & 45.5 & 10 & 40 & 0.8 \\
T3-4.5_1.6nfc & 4.5 & 45.5 & 10 & 40 & 1.6 \\
\hline
\end{tabular}

The relative content of NVP in vol.\% can be calculated from this table. 
brils and finally degassed with a vacuum pump. The curing conditions were similar to those used for the neat hydrogels.

\subsection{Characterization of hydrogel}

\subsubsection{Non-crosslinked species}

Neat and composite hydrogel cylinders $(10 \mathrm{~mm}$ in diameter and $5 \mathrm{~mm}$ in thickness) were vacuum dried for $24 \mathrm{~h}$ immediately after polymerization. This was followed by several cycles of washing in ethanol and deionized water to remove unreacted molecules over $24 \mathrm{~h}$ and finally vacuum-drying for $24 \mathrm{~h}$. The amount of non-crosslinked species $S$ was determined by

$S=\left(W_{1}-W_{2}\right) / W_{1}$

with $W_{1}$ the initial solid weight of the dried sample after polymerization and $W_{2}$ the weight of the dried sample after washing. For each concentration tested, the averaged sol content $S$ of three samples was determined.

\subsubsection{Equilibrium swelling ratio}

The swelling behavior was monitored gravimetrically by measuring the weight gain with time of immersion in phosphate-buffered saline (PBS) at room temperature. The samples were wiped off and weighed every $15 \mathrm{~min}$, until equilibrium was reached. The equilibrium swelling ratio $S R$ and fluid content $F C$ were calculated from:

$$
\begin{aligned}
S R & =W_{\mathrm{s}} / W_{\mathrm{d}}=\left(W_{\mathrm{w}}-W_{\mathrm{d}}\right) / W_{\mathrm{d}} \text { and } F C=W_{\mathrm{s}} / W_{\text {total }} \\
& =\left(W_{\mathrm{w}}-W_{\mathrm{d}}\right) /\left(W_{\mathrm{w}}+W_{\mathrm{d}}\right)
\end{aligned}
$$

where $W_{s}$ is the weight of PBS in the swollen hydrogel at equilibrium, $W_{\mathrm{w}}$ is the weight of the wet sample and $W_{\mathrm{d}}$ is the weight of the hydrogel before immersion (i.e. time 0 ).

\subsubsection{Static compression tests}

The mechanical properties of the hydrogels were also characterized by compressive unconfined stress-strain measurements which were performed on swollen gels using a UTS Z010 instrument (Zwick, Ulm, Germany). The cylindrical gel samples were loaded on the lower plate and compressed by the upper plate, which was connected to a load cell of $20 \mathrm{~N}$, at a strain rate of $1 \mathrm{~mm} \mathrm{~min}{ }^{-1}$. A pre-compressive load of $10 \mathrm{mN}$ was applied to the samples. The stress-strain curve being nonlinear, the behavior of the hydrogels was described but the phenomenological relationship used for different applications [27,28]:

$\sigma=\alpha[\exp (\beta \varepsilon)-1]$

with $\alpha$ and $\beta$ as the fitting parameters. When the deformation is small, $\alpha \times \beta$ corresponds to the elastic modulus at $0 \%$ strain. In order to compare the mechanical properties with values from several studies, we also report the value of the elastic modulus in the linear part of the stress-strain curve, which corresponds to a strain range of $20-25 \%$. We call this elastic modulus $E_{\text {lin }}$. All tests were carried out at $37^{\circ} \mathrm{C}$. Three samples were measured in each measurement, and the values were averaged.

\subsubsection{Shear tests}

The shear behavior of the neat hydrogel T3-4.5 and the composite hydrogel containing 4.5 vol.\% of T3 and 0.4 wt.\% of NFC (T34.5_0.4nfc) at swelling equilibrium was studied using an ARES apparatus (Rheometric Scientific Inc., New Jersey, USA) in parallel plate geometry. The plates were developed in the laboratory and were surrounded by an oil chamber to minimize the evaporation of water from the hydrogels during the experiments (Fig. 1). Dynamic frequency sweep tests were performed at room temperature with a preload under compression of $20 \%$ strain. A delay of $300 \mathrm{~s}$

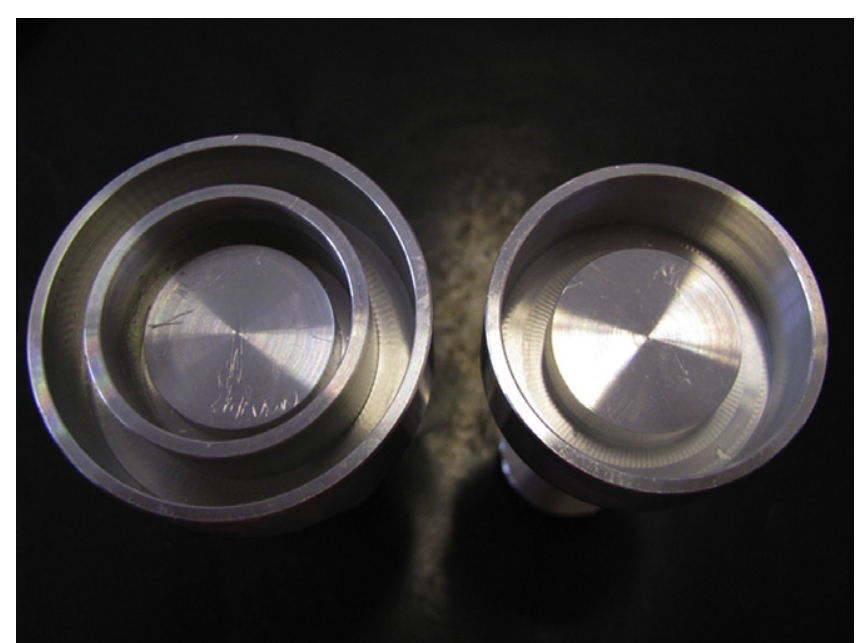

Fig. 1. Circular plates used for the shear tests. The upper element (right) is fitted into the lower part (left) to surround the plates with an oil chamber and thus create a humidity-tight chamber.

after the preload ensured the complete relaxation of the samples before the tests. A shear strain of $25 \%$ with frequencies from 1 to $100 \mathrm{rad} \mathrm{s}^{-1}$ was applied and nine points were taken per decade. Three specimens of each sample were tested and the resulting values were averaged.

\subsubsection{Cryo-SEM imaging}

The effect of NFC on the internal network of the hydrogels was observed by cryo-SEM imaging. Specimens with a diameter and height of about $100 \mu \mathrm{m}$ were cut with a blade and placed in an aluminum sample carrier (HPM, Bal-Tec/Leica, Vienna, Austria) with an outer diameter of $3 \mathrm{~mm}$ and a cavity of $200 \mu \mathrm{m}$ depth and $2 \mathrm{~mm}$ diameter.

High-pressure freezing (HPM, BalTec, Liechtenstein) was used to preserve the hydrated native porous structure of the hydrogels and to avoid ice crystal formation during freezing. Therefore, a pressure of 2200 bar was rapidly applied prior to freezing with supercritical liquid nitrogen. All the frozen specimens were subsequently stored in liquid nitrogen until further processing.

Cryo-fracturing was performed in liquid nitrogen by scratching the surface of the samples with a sharp blade in a VCT loading device (VCT 100, BalTec/Leica, Vienna, Austria). With the help of the VCT shuttle, freshly fractured samples were transferred from the liquid nitrogen under a dry nitrogen atmosphere into a freeze-etching device (BAF060, BalTec/Leica, Vienna, Austria) pre-cooled to $-140{ }^{\circ} \mathrm{C}$ under high vacuum.

The freeze-etching system was used to perform the sublimation of water on the surface of the specimens. Therefore, the temperature and pressure were set to $-100^{\circ} \mathrm{C}$ and $1 \times 10^{-6}$ $2 \times 10^{-7}$ mbar, respectively, for $30 \mathrm{~min}$.

Finally, the samples were cooled down to $-120^{\circ} \mathrm{C}$ again and rotary shadowed from an elevation angle of $45^{\circ}$ with tungsten to an average layer thickness of $3 \mathrm{~nm}$. The frozen and coated samples were then transferred under a high vacuum $\left(2 \times 10^{-7}\right.$ mbar $)$ at $-20{ }^{\circ} \mathrm{C}$ from the versatile cryo-transfer system VCT to the precooled cryo-stage set at $-120^{\circ} \mathrm{C}$ in a field emission scanning electron microscope (LEO Gemini 1530, Carl Zeiss, Oberkochen, Germany). Images were recorded at $-120^{\circ} \mathrm{C}$ and at an acceleration voltage of $2 \mathrm{kV}$.

\subsection{Biocompatibility}

Human fetal cartilage cells from a 14 week fetus were obtained from our dedicated cell banks (University Hospital of Lausanne, 
Switzerland (Ethical Protocol \# 51/01)). They were cultured in basal Dulbecco's modified Eagle's medium (Invitrogen, Carlsbad, CA) supplemented with $1 \%$ L-glutamine (Invitrogen) and 10\% fetal calf serum (Sigma-Aldrich, St. Louis, MO), and maintained at $37{ }^{\circ} \mathrm{C}$ in a humidified $5 \% \mathrm{CO}_{2}$ atmosphere. The culture medium was changed twice per week. The cells used were between the third and fifth passages.

The hydrogel samples were swollen until equilibrium in PBS in small flasks and then sterilized in an autoclave at $120^{\circ} \mathrm{C}$ during $20 \mathrm{~min}$.

To evaluate the biocompatibility of the T3-4.5 hydrogel, fetal cells were seeded at 3000 cells $\mathrm{cm}^{-2}$ in Petri dishes at a distance of $0.5 \mathrm{~cm}$ around the gel, with no contact between the gel and the cells, and incubated for $\sim 1$ week in the culture conditions described above. Fresh culture medium was added twice weekly for cell proliferation. Giemsa staining was then used to stain the cells and the hydrogel, and to observe the hydrogel-cell interface and the cell's morphology, as described previously [29]. Blanks consisted of cells without the hydrogel. Experiments were performed twice, with three specimens per sample.

\section{Results}

\subsection{Synthesis of $\mathrm{T3}$}

The general synthetic route for coupling a vinyl moiety with a hydroxylated polymer was first described by Hennink and van Nostrum [30] and the grafting of dextran with glycidyl methacrylate was performed by Cavalieri et al. [31] and Dijk-Wolthuis et al. [32]. The Tween ${ }^{\circledR} 20$ hydroxyl end groups react with the methacryl moieties of the chloride in the presence of a base (DMAP), which acts as a catalyst to form T3, as shown in Scheme 1. FTIR spectra for Tween ${ }^{\circledR} 20$ and T3 are shown in Fig. 2, where differences can be noted between the two spectra. The modification of Tween ${ }^{\circledR}$ 20 induced the disappearance of the $-\mathrm{OH}$ absorption band $\left(v_{\mathrm{OH}}\right)$ at $3500 \mathrm{~cm}^{-1}$, an increase in the carbonyl stretching vibration at $1200 \mathrm{~cm}^{-1}\left(v_{\mathrm{C}=0}\right.$, methacrylate $)$ and the appearance of two peaks, at
$1100 \mathrm{~cm}^{-1}\left(v_{\mathrm{C}-\mathrm{O} \text {, methacrylate }}\right)$ and $813 \mathrm{~cm}^{-1}\left(v_{\mathrm{C}-\mathrm{H}, \mathrm{CH}=\mathrm{CH}_{2}}\right)$, respectively. These results were consistent with the conversion of the $-\mathrm{OH}$ groups into methacrylate groups. Except for these modifications, the two spectra were identical, suggesting that there was no modification of the Tween ${ }^{\circledR} 20$ monomer backbone after reaction. The success of the reaction was further confirmed by ${ }^{1} \mathrm{H}$ NMR spectroscopy (Fig. 3). Tween ${ }^{\circledR} 20$ is characterized by chemical shifts at $\delta 0.8,1.2,1.6,3.65$ and $4.2 \mathrm{ppm}$. The peak at $\delta 3.65 \mathrm{ppm}$ is characteristic of the poly(ethylene glycol) (PEG) structure and represents the inner protons, whereas that at $\delta 4.2 \mathrm{ppm}$ is representative of the protons adjacent to the end groups. These peaks were present in both spectra, again indicating that the backbone of the molecule remained unchanged after reaction. The lack of additional peaks other than those associated with the methacrylate moieties in the T3 spectra suggests that the unreacted compounds were quantitatively removed. Peaks at $\delta 5.6$ and $6.1 \mathrm{ppm}$ are reported for the methylene protons of methacrylate groups of T3. The peak at $\delta 4.2 \mathrm{ppm}$ corresponded to the protons adjacent to the hydroxyl groups in the Tween ${ }^{\circledR} 20$ molecule. After methacrylation, an additional peak was observed at $\delta 4.3 \mathrm{ppm}$, due to protons adjacent to the newly added methacrylate moieties. Unreacted hydroxyl groups could not be distinguished in the spectra owing to overlap with the inner proton peak at $\delta 3.65 \mathrm{ppm}$. In order to quantify the degree of methacrylation, the peak at $\delta 1.2 \mathrm{ppm}$, which corresponds to 18 of the olefinic protons, was used as a reference. The calculated DS of 3.12 confirmed the full conversion of hydroxyl moieties into methacrylate moieties within the accuracy of the measurement (experimental error $<5 \%$ ).

\subsection{Hydrogel non-crosslinked species}

Fig. 4 presents the evolution of the hydrogel sol contents as functions of the crosslinker (Fig. 4a) and initiator (Fig. 4b) concentrations. Fig. 4a shows that, for all the hydrogels studied (T3-4.5, T3-8, T3-11.5 and T3-15), the amount of non-crosslinked species decreased with increasing T3 concentration from $51.7 \pm 2.3 \%$ to $39.1 \pm 2.6 \%$. This trend was attributed to an increase in crosslinked network formation with the T3 concentration, as expected.

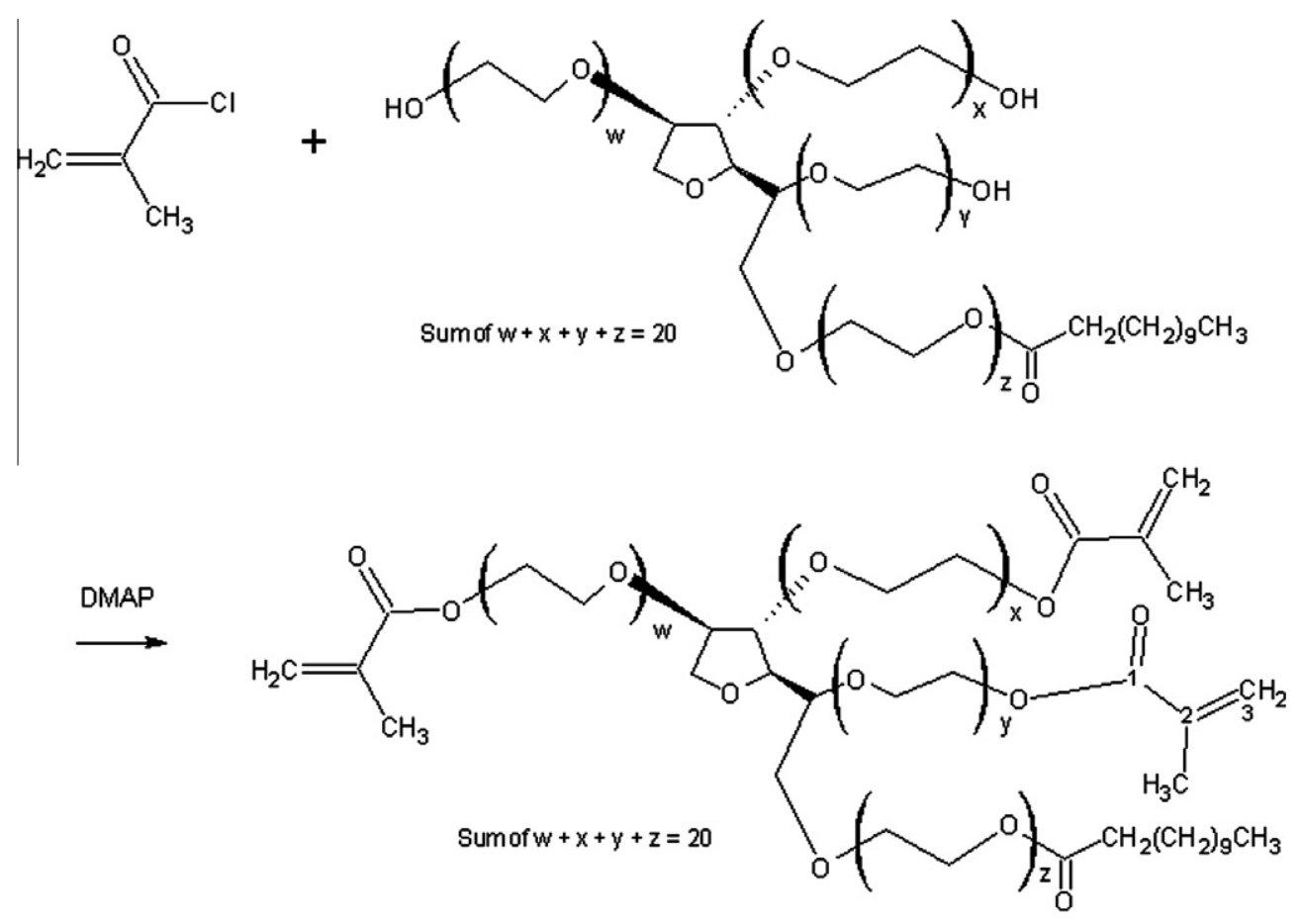

Scheme 1. The reaction of Tween ${ }^{\circledR} 20$ with $\mathrm{MeOCl}$ in the presence of DMAP to form T3 molecules. 


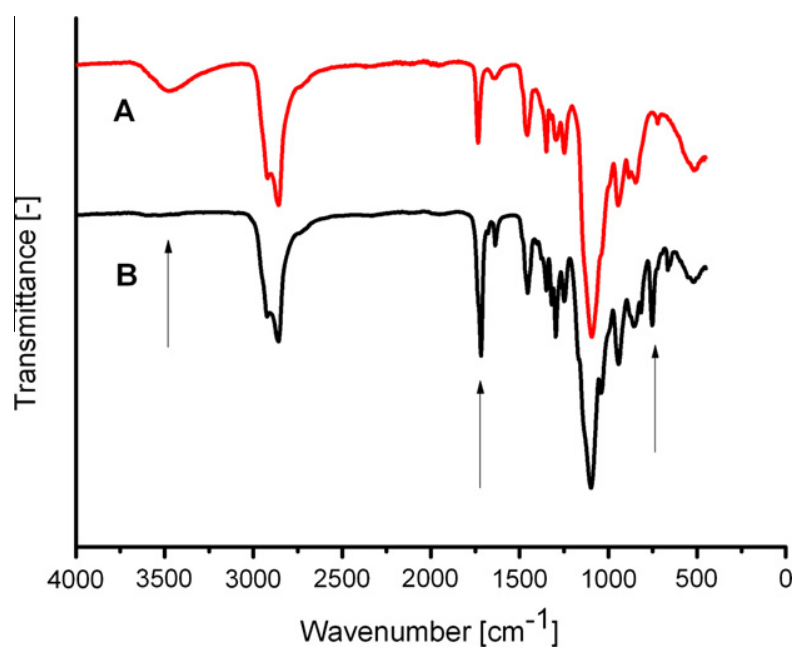

Fig. 2. Transmittance FTIR spectra of the initial Tween ${ }^{\circledR} 20(\mathrm{~A})$ and the final T3 (B). The selected peaks are assigned as follows: $3500\left(v_{\mathrm{O}-\mathrm{H}}\right), 2900\left(v_{\mathrm{C}-\mathrm{H}}\right), 1710\left(v_{\mathrm{C}=0}\right)$, $1100\left(v_{\mathrm{C}-\mathrm{O}, \text { ester }}\right), 813\left(v_{\mathrm{C}-\mathrm{H}, \mathrm{CH}=\mathrm{CH}_{2}}\right)$. The disappearance of the $-\mathrm{OH}$ groups and the appearance of the $\mathrm{C}-\mathrm{O}, \mathrm{C}-\mathrm{H}$ and $\mathrm{CH}=\mathrm{CH}_{2}$ illustrate the formation of methacrylate groups.

Fig. $4 \mathrm{~b}$ shows the influence of the photoinitiator on the amount of non-crosslinked species for three different hydrogels, containing 8 vol.\% of T3 and 10, 30 and 50 vol.\% of initiator solution (T3-8, T38_30init and T3-8_50init, respectively). The non-crosslinked species content reached a minimum value for T3-8_30init, with the
T3-8_50init again showing a larger amount of non-crosslinked species. This was associated with an increase in steric hindrance with the initiator concentration. Hence, methacrylate crosslinking might have been occurred faster with larger amounts of initiator, thus increasing the viscosity of the solution and decreasing the mobility of the methacrylate molecules. The reproducibility of the measurements with the largest amount of initiator is poorer owing to the mechanism of network formation. Indeed, a large amount of initiator will induce premature chain termination and will therefore favor a high number of uncrosslinked chains that will not be incorporated in the network. However, due to physical entanglement, some of these chains will remain in the network even after the washing step, which could bias the measurements.

Concerning the nanocomposite hydrogels reinforced with NFC, only one fiber concentration was tested, because the subsequent washing and drying of the NFC within the samples completely disintegrated the hydrogels with high NFC contents. This might be due to the hornification of the NFC. The neat hydrogel T3-4.5 had a non-crosslinked species amount of $51.7 \pm 2.3 \%$ and the composite hydrogel T3-4.5_0.4nfc showed an amount of $40.2 \pm 4.9 \%$, which was comparable to the non-crosslinked species amount of the highest crosslinked hydrogel T3-15.

\subsection{Swelling ratio}

The diffusion of fluids into hydrogels, their related mass changes and their swelling ratios are influenced by the crosslinking density, gel composition, charge density or filler content and other parameters [33]. Neat hydrogels with three different T3 concentra-

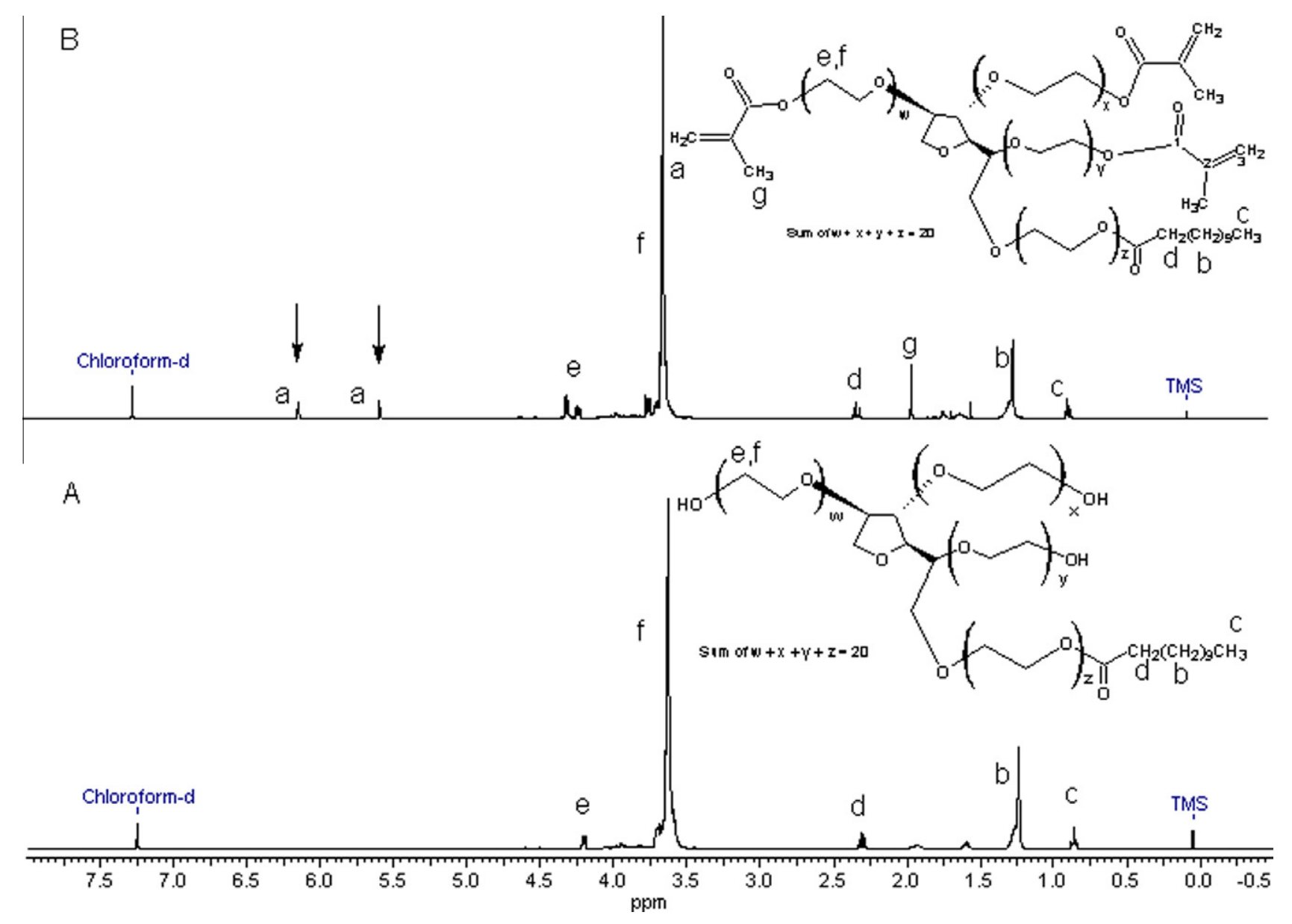

Fig. 3. ${ }^{1} \mathrm{H}$ NMR spectra of Tween ${ }^{\circledR} 20$ (A) and T3 (B). The peak variations confirm the methacrylation. 

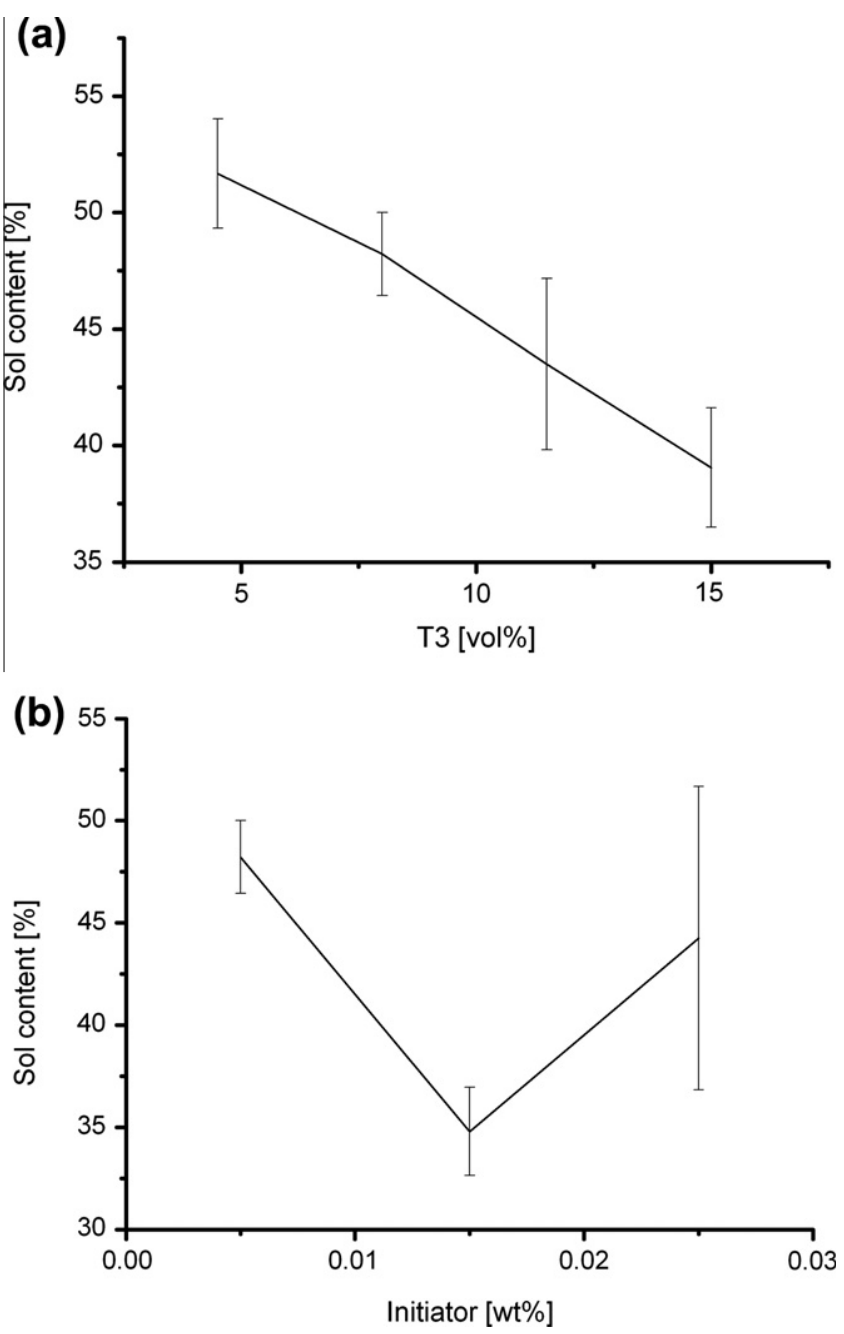

Fig. 4. Amount of non-crosslinked species in hydrogels. (a) The concentration of T3 clearly promotes more crosslinking. (b) The optimum UV initiator concentration (wt.\% corresponding to 10,30 and 50 vol.\% respectively) for the hydrogels containing $8 \mathrm{vol} . \%$ of T3 is higher than $30 \mathrm{vol} . \%$ to produce a more crosslinked network.

tions (4.5, 8 and 15 wt.\%, respectively) and composite hydrogels thereof with two different NFC concentrations (0.4 and 0.8 wt.\%) were tested. All the T3/NVP hydrogels studied show similar mass uptake (Fig. 5) and swelling behavior, with an initial rapid fluid intake and swelling phase at short times, before the penetrant uptake slows at intermediate times, the hydrogels become fully swollen and asymptotic equilibrium fluid content $(F C)$ and swelling ratio $(S R)$ are reached (Table 2 ). The equilibrium swelling ratios decreased from 5.7 to 1.5 with increasing T3 content. A 3-fold increase in crosslinker resulted in an $S R$ three times lower, showing a linear relationship between the T3 content and the $S R$ over the concentration range analyzed. The least crosslinked network (i.e. the hydrogel with the largest amount of non-crosslinked species, T3-4.5) also presented the highest SR.

The swelling ratios of the neat and composite hydrogels reinforced with NFC are presented in Fig. 6. Compared with the SRs of the neat hydrogels, the SRs of the composite hydrogels clearly decreased with increasing NFC concentration. However, for smallest concentration of NFC tested (0.4 wt.\%), this decrease was less significant than for the higher NFC concentrations. From these results, we can conclude that, in the case of composite hydrogels, the $S R$ is still controlled more by the T3 content than by the amount of NFC.

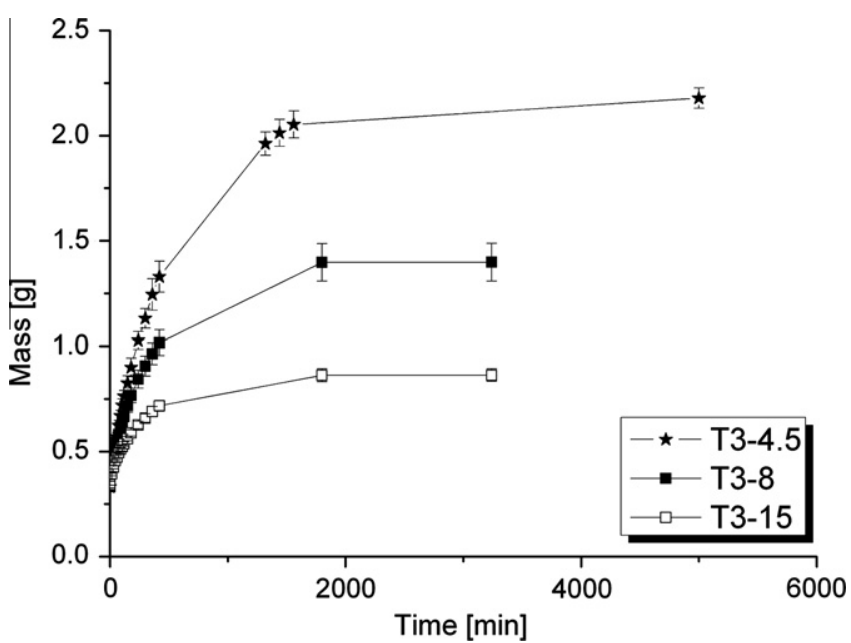

Fig. 5. Mass variations of hydrogels during their immersion in PBS for three different concentrations of T3 $(4.5,8$ and 15 vol.\%). The least crosslinked network (4.5 vol.\% T3) absorbs the most liquid.

Table 2

Fluid content and swelling ratio of fully hydrated hydrogels.

\begin{tabular}{lll}
\hline Neat and composite hydrogels & Swelling ratio SR (-) & Fluid content (FC) (\%) \\
\hline Neat T3-4.5 & $5.7 \pm 0.4$ & $73.5 \pm 1.7$ \\
Neat T3-8 & $3.2 \pm 0.3$ & $61.4 \pm 2.5$ \\
Neat T3-15 & $1.5 \pm 0.2$ & $43.1 \pm 3.2$ \\
T3-4.5_0.4nfc & $5.4 \pm 0.2$ & $73.1 \pm 0.8$ \\
T3-8_0.4nfc & $3.1 \pm 0.3$ & $60.9 \pm 2.3$ \\
T3-15_0.4nfc & $1.4 \pm 0.1$ & $41.9 \pm 1.9$ \\
T3-4.5_0.8nfc & $4.3 \pm 0.4$ & $67.2 \pm 2.0$ \\
T3-8_0.8nfc & $2.7 \pm 0.1$ & $58.0 \pm 1.1$ \\
T3-15_0.8nfc & $1.1 \pm 0.1$ & $35.9 \pm 2.0$ \\
\hline
\end{tabular}

For the desired application, a high swelling ratio is required. Therefore, further testing was limited to composite hydrogels containing 4.5 wt.\% of T3 with varying NFC contents.

\subsection{Static compression tests}

Neat hydrogels of composition T3-4.5 and composite hydrogels with the same T3 content and different NFC concentrations (0.2, $0.4,0.8$ and $1.6 \mathrm{wt} . \%$, respectively) were tested in static compression. Fig. 7 shows typical compressive stress-strain curves of the hydrogels. For clarity, not all of the curves are presented; nevertheless, a greater scatter was observed for the $1.6 \mathrm{wt}$.\% NFC (stresses between 9 and $16 \mathrm{kPa}$ at 25\% strain) than for the other concentrations. The stress-strain curves of swollen hydrogels are not linear and the behavior of such a material is viscoelastic. As the concentration of NFC increases, the curves are shifted towards higher values of stress, indicating the reinforcement of the network with NFC.

To describe such nonlinear stress-strain curves, Eq. (3) was used, and the corresponding values of $\alpha$ and $\beta$ are reported in Table 3. As can be seen in Fig. 8, the constitutive law (Eq. (3)) described the experimental data adequately. The linear part of the stress-strain (20-25\%) curve was used to calculate the elastic modulus $E_{\text {lin, }}$ and its value is reported in Table 3 . The standard deviations are small for low NFC concentrations, indicating reproducible results and homogeneous hydrogels. The composite hydrogels showed an increase in the moduli $E$ and $E_{\text {lin }}$ with increasing concentrations of NFC. The increase was very significant with only a small amount of NFC ( $0.2 \mathrm{wt} . \%)$, with an increase in the modulus of about 3 -fold. With the highest concentration of NFC, $E_{\text {lin }}$ was 


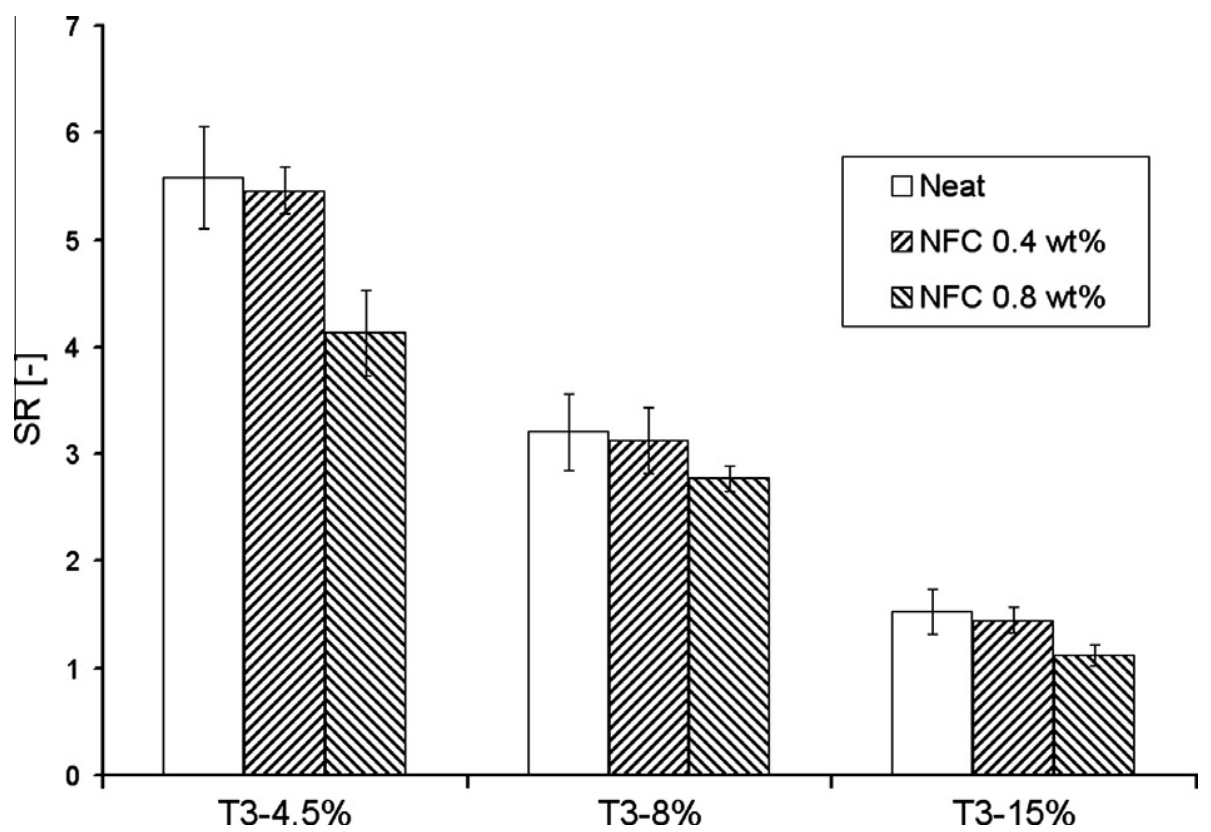

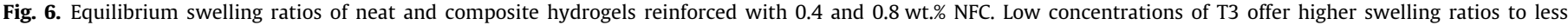
crosslinked polymer networks. The swelling of composite hydrogels decreases with the addition of more cellulose fibrils.

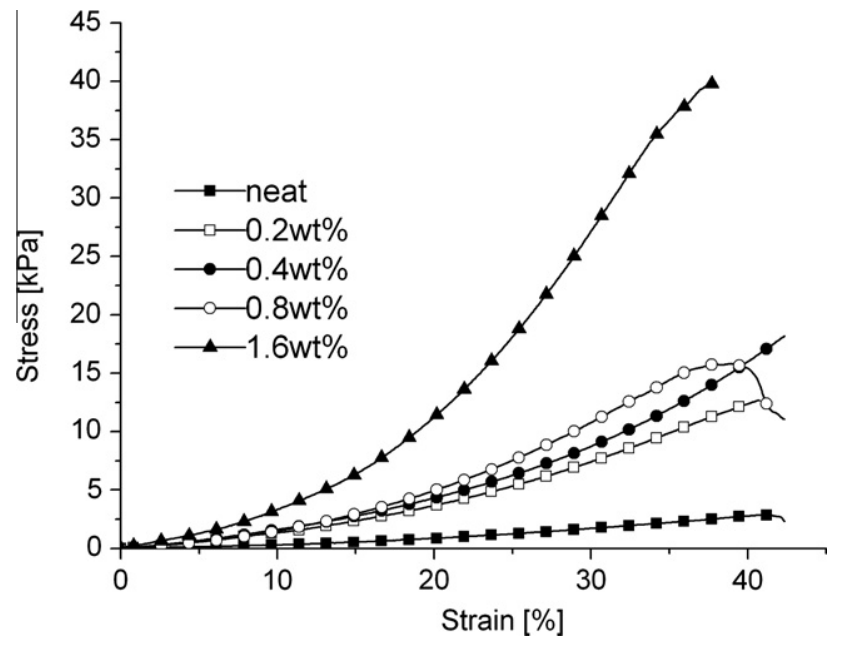

Fig. 7. Representative stress-strain curves in compression of neat and composite hydrogels with different NFC concentrations in wt.\%, as performed at room temperature on samples at swelling equilibrium. As the amount of NFC increases, the nonlinear curves are shifted towards higher values of stress, indicating a reinforcement of the network by the NFC. Furthermore, the stiffness of the composite hydrogel is also improved by the addition of more NFC.

increased around 8-fold, but the results for this concentration were not very reproducible owing to a difficulty in controlling the dispersion of fibers at such a high concentration of NFC.

Table 3

Fitting parameters $\alpha$ and $\beta$ determined from Eq. (3), $E$ at $0 \%$ strain $(\alpha * \beta)$ and $E_{\text {lin }}$ between $20 \%$ and $25 \%$ of strain for neat and composite hydrogels.

\begin{tabular}{lcllr}
\hline & $E(20-25 \%)(\mathrm{kPa})$ & $\alpha(\mathrm{kPa})$ & $\beta(-)$ & $\alpha * \beta(\mathrm{kPa})$ \\
\hline T3-4.5 & $7.42 \pm 1.05$ & $0.77 \pm 0.30$ & $3.92 \pm 0.52$ & $2.90 \pm 0.72$ \\
T3-4.5_0.2nfc & $22.77 \pm 2.78$ & $2.99 \pm 1.05$ & $3.43 \pm 0.72$ & $9.96 \pm 2.11$ \\
T3-4.5_0.4nfc & $29.29 \pm 0.11$ & $2.18 \pm 1.57$ & $4.78 \pm 1.50$ & $11.78 \pm 1.27$ \\
T3-4.5_0.8nfc & $37.80 \pm 1.06$ & $2.70 \pm 1.54$ & $4.80 \pm 1.47$ & $13.87 \pm 1.77$ \\
T3-4.5_1.6nfc & $62.17 \pm 8.30$ & $3.49 \pm 1.49$ & $5.47 \pm 1.18$ & $17.92 \pm 4.47$ \\
\hline
\end{tabular}

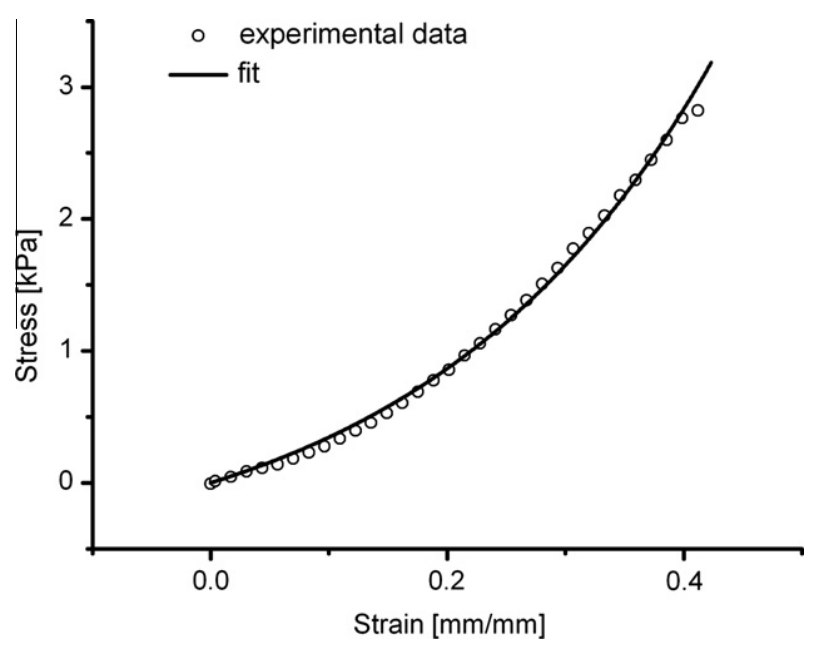

Fig. 8. Compressive stress-strain curve for a T3-4.5 hydrogel ( $0.4 \mathrm{wt} . \%$ of NFC) at room temperature and swelling equilibrium. The nonlinear constitutive law (Eq. (3)) describes the experimental data adequately.

The hydrogels containing the least amount of PBS in their network, i.e. the hydrogels with the lowest swelling ratio, have the highest elastic moduli, showing that the stiffness of the network is also defined by the PBS content in the latter. The reinforcement effect of NFC was therefore proved. All composite hydrogels have elastic moduli in the same range as those determined for the native NP. The neat hydrogel moduli are in the lower range of the NP moduli, indicating that only composite hydrogels should be considered for NP replacement, with the exception of hydrogels containing $1.6 \mathrm{wt} . \%$ of NFC, where the results were less reproducible. Therefore, combining the swelling and compression results, the best compromise is the composite hydrogel T3-4.5_0.4nfc.

\subsection{Shear properties}

Fig. 9a presents the storage $\left(G^{\prime}\right)$ and loss $\left(G^{\prime \prime}\right)$ moduli of the neat and composite hydrogels (i.e. T3-4.5_0.4nfc) as a function of the 
shear frequency. For all the hydrogels tested, the storage values were systematically higher than the loss values over the entire frequency range (1-100 rad s$~^{-1}$ ) with $G^{\prime}$ in the order of $10^{3} \mathrm{~Pa}$, indicating an elastic solid behavior [34]. $G^{\prime}$ and $G^{\prime \prime}$ generally increased as the frequency increased for both neat and composite hydrogels, which indicates a relaxation of the network at higher frequencies. Both $G^{\prime}$ and $G^{\prime \prime}$ increased for the composite hydrogel compared to values measured for the neat material. After about $35 \mathrm{rad} \mathrm{s}^{-1}$, a change in slope was observed for the two moduli of both hydrogels, which was also confirmed by the evolution of the damping factor with shear frequency $(\tan \delta)$ (Fig. 9b). The elastic component becomes more important, causing the decrease in $\tan \delta$ for both hydrogels. Comparison of the two hydrogels shows that the increase in $G^{\prime}$ was more significant than the increase in $G^{\prime \prime}$, thus indicating that the composite hydrogel behaves more like an elastic solid than the neat one. The increase in $\tan \delta$ of both hydrogels was pronounced at low frequencies.

The calculated dynamic complex shear moduli $\left|G^{*}\right|$ and $\delta$ ranged from $0.77 \pm 0.02$ to $1.16 \pm 0.06 \mathrm{kPa}$ and from $4.74 \pm 0.75^{\circ}$ to $6.70 \pm 1.35^{\circ}$, respectively, for the neat hydrogels, and from $1.88 \pm 0.93$ to $2.35 \pm 0.98 \mathrm{kPa}$ and from $6.33 \pm 0.86^{\circ}$ to $9.55 \pm 2.76^{\circ}$, respectively, for the composite hydrogels. These two values are measures of the dissipative ability of the material.
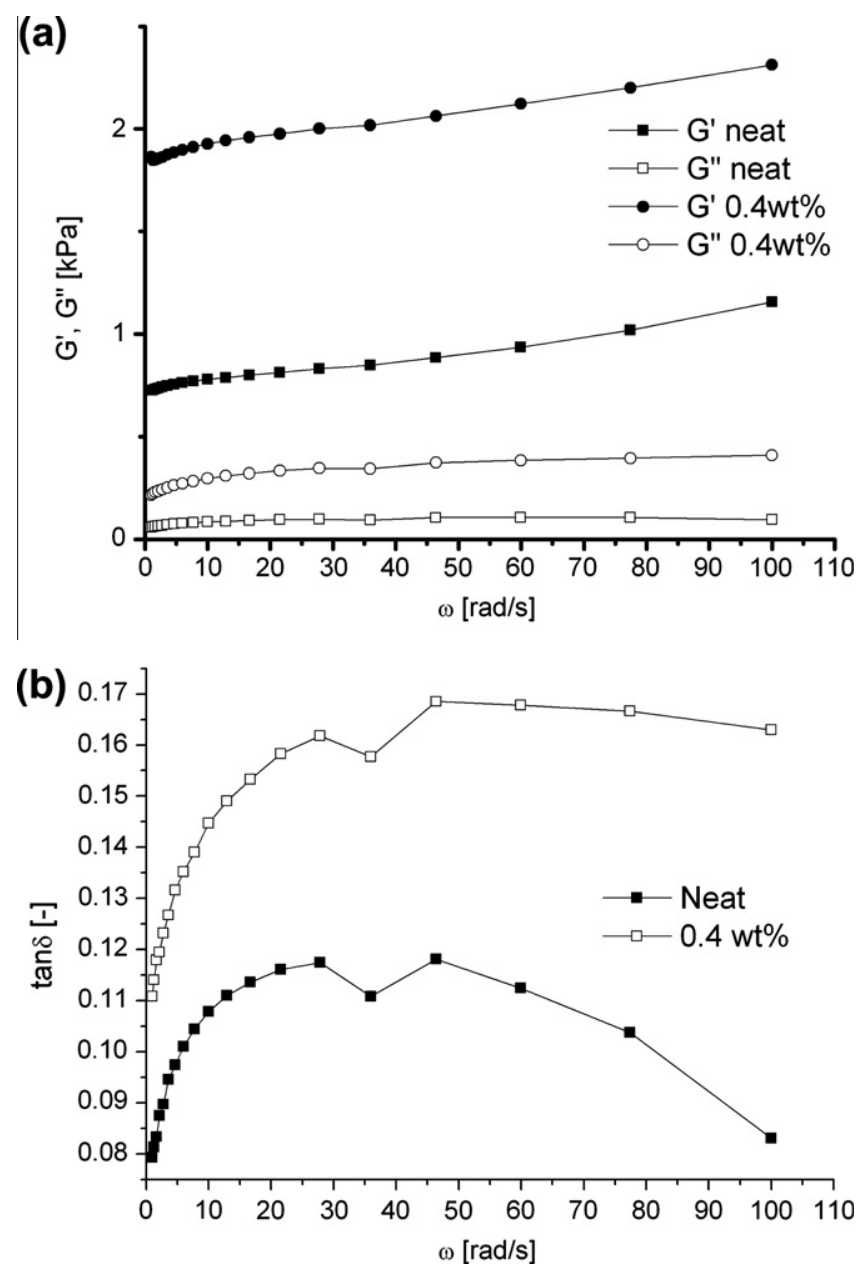

Fig. 9. Properties of T3-4.5 neat and composite hydrogels under shear stress. (a) The storage modulus ( $G^{\prime}$, solid symbols), the loss modulus ( $G^{\prime \prime}$, hollow symbols) and (b) the damping factor $(\tan \delta)$ evolve with the shear frequency at room temperature. The composite is stiffer than the neat hydrogel while exhibiting higher dissipative ability.

\subsection{Cryo-SEM imaging}

The morphology of the neat and composite hydrogel networks was observed by SEM, as shown in Fig. 10. A very porous structure was observed for both hydrogels, with pore size in the order of $100 \mathrm{~nm}$ and lower. The neat hydrogel presented a very homogeneous crosslinked structure and no cluster of polymer chains could be observed. When adding NFC to the network, the observed structure changed, but a clear differentiation of the NFC from the polymer chains was not possible. It can, however, be confirmed that a good dispersion of the fibrils was obtained because very little NFC agglomeration was observed.

\subsection{Biocompatibility}

Cartilage fetal cells seeded around the neat hydrogels were used as a preliminary assessment to determine the biocompatibility of the material. Only cells attached to the Petri dish could be fixed and colored, indicating that only living cells are shown in Fig. 11. The cells do not present any granulation or anomalous morphology, indicating that neither the hydrogel nor any non-crosslinked monomer has an effect on cell' metabolism.

\section{Discussion and conclusions}

Biological materials are complex, dynamic and multi-functional, and these properties are difficult to achieve in purely synthetic systems. It was previously believed that artificial biomaterials needed to provide high strength associated with a high elasticity modulus at low strain levels [35] for soft tissue replacement. However, soft biological tissues are characterized by large strains before failure and are tough and flexible. In order to avoid a mechanical mismatch between replacement materials and soft tissue, the design of new materials has to mimic the structure of the natural materials, in this case the NP [20]. This biomimetic approach has been used here to design a cellulose nanofibril-reinforced hydrogel, which is able to match the swelling and mechanical properties of the native NP. The ideal parameters have already been outlined by Bao et al. [5] for an ideal NP replacement. They suggest choosing a material with a stiffness greater than or equal to the native NP. The elasticity modulus at $20 \%$ strain, corresponding to $E_{\text {lin }}$ in our study, reported for the NP, is $5.39 \pm 2.56$ [15] in compression. The appropriate choice of molecule for such a material is therefore of paramount importance. Hydrogels made of methacrylates, and mostly PEG-dimethacrylates, are widely used in biological applications [36]. Linear elastic moduli reported for PEG-based hydrogels used for tissue engineering are about $0.1 \mathrm{kPa}$ [37]. As shown in this study, the three-branched methacrylate molecule T3 allows a 30fold increase in the modulus of the neat hydrogel.

In our study, the amount of non-crosslinked species of the polymerized T3-NVP hydrogels is in the range of $30-50 \%$, which is in agreement with the values reported for the photopolymerization of methacrylate-NVP-based hydrogels [38]. Unreacted molecules of T3 and NVP are still present in the network after polymerization, but only low cytotoxicity of unreacted methacrylates and NVP $[39,40]$ has been reported so far.

The native NP is composed of a matrix containing randomly dispersed collagen fibers which allow a higher elastic modulus and dissipation of load through the surrounding structures [13]. All composite hydrogels tested in this work presented a three- to 8 -fold increase in elastic modulus compared to neat hydrogel, from $7.42 \pm 1.05$ to $62.17 \pm 8.30 \mathrm{kPa}$, depending on the NFC concentration and the method used to determine the modulus, which is above the value for the native NP. The modulus at $0 \%$ strain given in the literature for the human NP is $3.25 \pm 1.56 \mathrm{kPa}$ [15], and in 

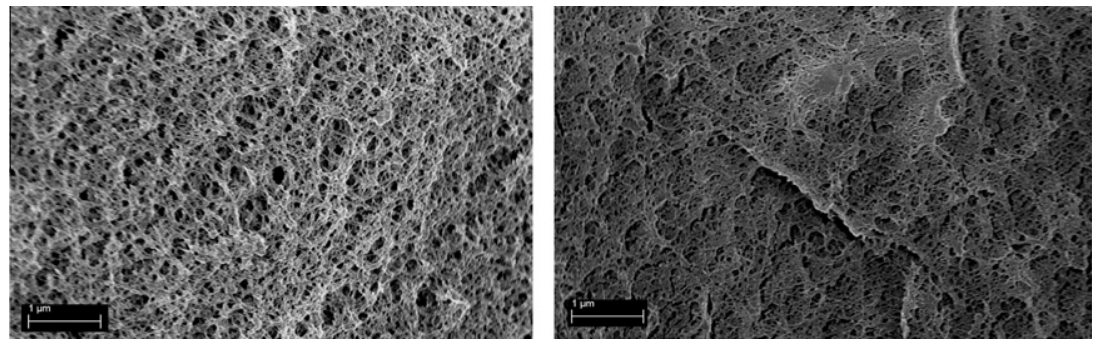

Fig. 10. Cryo-SEM micrographs of neat (left) and composite hydrogel containing 0.4 wt.\% NFC (right). Both materials have a homogeneous porous microstructure.
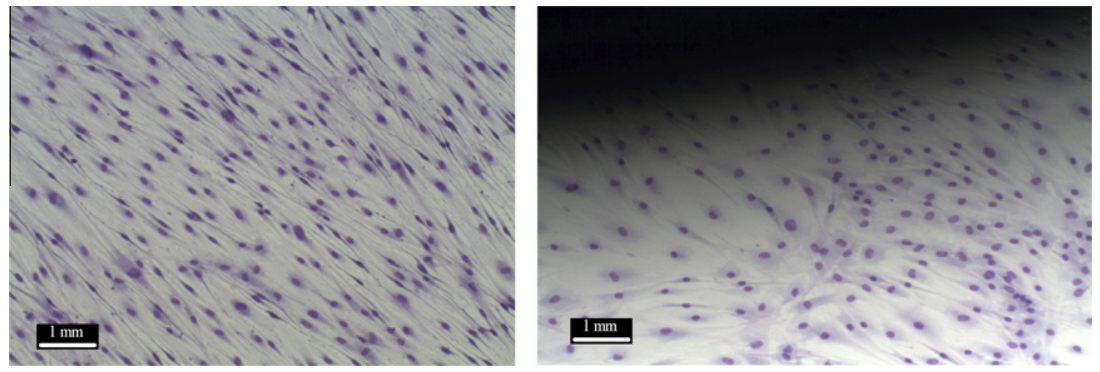

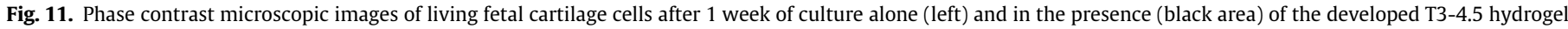
(right). The cell seeding density is 3000 cells $\mathrm{cm}^{-2}$.

this study the elastic modulus at $0 \%$ strain was determined from $\alpha$ and $\beta$ (Table 3 ). Here again, the modulus increases with NFC content and is higher than the value for the human NP. The dissipation of loads was assessed with shear measurements, from which the complex shear modulus $\left|G^{*}\right|$ and the angle $\delta$ were calculated. Generally, the dynamic mechanical properties of a hydrogel depend on the density of the polymer chains, the friction between the chains and the homogeneity of the intrinsic network structure $[41,42]$. Incorporation of NFC not only increases the friction, but also increases the value of $\delta$, thus leading to higher complex dynamic moduli and therefore increased load dissipation of composite hydrogels. These values are lower than the values for the human NP observed by latridis et al. [16], who reported values for $\left|G^{*}\right|$ of $7-21 \mathrm{kPa}$ and values for $\delta$ of $23-30^{\circ}$. However, the composite hydrogels showed increasing load dissipation with increasing NFC content compared to the neat hydrogels. The deviating rheological behaviors of the neat and composite hydrogels are due to their different network structures. Although different forces compression, shear, tension - act on each spine segment, it can be assumed that in daily life the loads transmitted through the NP are mainly compressive [4]. As mentioned earlier, the developed composite hydrogel fulfils the requirements in compression.

A functional NP replacement should restore the disc height and the loading of the AF in order to keep the biomechanics of the spine intact. However, as observed in the SEM images, the pore sizes of all the hydrogels studied were too small for cell proliferation. Consequently, the NP implant in this work was not designed for cell proliferation within the scaffold but rather for high mechanical and swelling properties. The viability of living cells in contact with the neat hydrogel was observed, rendering this composite hydrogel a suitable candidate for human implantation. Of course, these results provide only limited information on biocompatibility, and further tests are required. Nevertheless, as cellulose has been used in a wide range of biomedical applications, such as scaffolds for cartilage engineering, and has proved to be biocompatible [43], the composite hydrogel can now be considered for further cytotoxicity, gene expression and in vivo tests.

The data presented in this study have shown that hydrogels with high elastic moduli had lower swelling ratios. These two properties are co-dependent and both need to be taken into account when choosing the best candidate for replacing the NP. The composite hydrogel containing 4.5 vol.\% of T3 and $0.4 \mathrm{wt} . \%$ of NFC combined the desired swelling with mechanical performance and could be the most suitable candidate for NP replacement. Future studies should consider the long-term evolution and cyclic loading of the proposed composite hydrogel and investigate the potential of fiber modification to increase the swelling capacity further without hindering the mechanical properties of the composite hydrogel.

\section{Acknowledgements}

The financial funding from the Swiss National Science Foundation (205320-121893) is gratefully acknowledged. The authors thank Sandra Jaccoud (Laboratory of Biomechanical Orthopedics) for the supply of cells and help with the cell study. Dr. med. Constantin Schizas and Dr. Christopher Plummer are acknowledged for valuable advice and Dr. Roger Wepf, Electron Microscopy of ETH (EMEZ), is acknowledged for his support concerning high pressure freezing, cryo-fracturing and cryo-SEM imaging.

\section{Appendix A. Figures with essential colour discrimination}

Certain figures in this article, particularly Figs. 1-3 and 11, are difficult to interpret in black and white. The full colour images can be found in the on-line version, at doi:10.1016/j.actbio.2011. 05.029 .

\section{References}

[1] Urban JPG, Roberts S. Degeneration of the intervertebral disc. Arthritis Res Ther 2003;5(3):120-30.

[2] Anderson DG, Tannoury C. Molecular pathogenic factors in symptomatic disc degeneration. The Spine J 2005;5(6 Suppl. 1):S260-6.

[3] Antoniou J, Steffen T, Nelson F, Winterbottom N, Hollander AP, Poole RA, et al. The human lumbar intervertebral disc: evidence for changes in the biosynthesis and denaturation of the extracellular matrix with growth, maturation, ageing, and degeneration. J Clin Invest 1996;98(4):996-1003.

[4] White III AA, Panjabi M. Clinical biomechanics of the spine. 2nd ed. Philadelphia: J.B. Lippincott Company; 1990. 
[5] Bao QB, McCullen GM, Higham PA, Dumbleton JH, Yuan HA. The artificial disc: theory, design and materials. Biomaterials 1996;17(12):1157-67.

[6] Ferguson SJ, Ito K, Nolte LP. Fluid flow and convective transport of solutes within the intervertebral disc. J Biomech 2004;37(2):213-21.

[7] Ferguson SJ, Steffen T. Biomechanics of the aging spine. Eur Spine 2003;12(Suppl. 2):S97-S103.

[8] Bono CM, Garfin SR. History and evolution of disc replacement. Spine J 2004;4(6 Suppl.):145S-50S

[9] Lee CK, Goel VK. Artificial disc prosthesis: design concepts and criteria. Spine J 2004;4(6 Suppl.):209S-18S.

[10] Goins ML, Wimberley DW, Yuan PS, Fitzhenry LN, Vaccaro AR. Nucleus pulposus replacement: an emerging technology. Spine J 2005;5(6 Suppl.):317S-24S

[11] Mizuno H, Roy AK, Zaporojan V, Vacanti CA, Ueda M, Bonassar LJ Biomechanical and biochemical characterization of composite tissueengineered intervertebral discs. Biomaterials 2006;27(3):362-70.

[12] Galante JO. Tensile properties of the human lumbar annulus fibrosus. Acta Orthop Scand 1967(Suppl. 100):1-91.

[13] Yu J, Winlove PC, Roberts S, Urban JP. Elastic fibre organization in the intervertebral discs of the bovine tail. J Anat 2002;201(6):465-75.

[14] Rannou F, Mayoux-Benhamou MA, Poiraudeau S, Revel M. Disque intervertébral et structures voisines de la colonne lombaire: anatomie, biologie, physiologie et biomécanique [Anatomy, biology, physiology, and biomechanics of intervertebral disk and other anatomical structures of the lumbar spine]. EMC-Rhumatol-Orthop 2004;1(6):487-507.

[15] Cloyd JM, Malhotra NR, Weng L, Chen W, Mauck RL, Elliott DM. Materia properties in unconfined compression of human nucleus pulposus, injectable hyaluronic acid-based hydrogels and tissue engineering scaffolds. Eur Spine J 2007;16(11):1892-8.

[16] Iatridis JC, Setton LA, Weidenbaum M, Mow VC. The viscoelastic behavior of the non-degenerate human lumbar nucleus pulposus in shear. J Biomech 1997;30(10):1005-13.

[17] Bao QB, Yuan HA. Prosthetic disc replacement: the future? Clin Orthop Related Res 2002(394):139-45.

[18] Joshi A, Fussell G, Thomas J, Hsuan A, Lowman A, Karduna A, et al. Functional compressive mechanics of a PVA/PVP nucleus pulposus replacement. Biomaterials 2006;27(2):176-84.

[19] Hoffman AS. Hydrogels for biomedical applications. Adv Drug Deliv Rev 2002;54(1):3-12.

[20] Kopecek J. Hydrogels: from soft contact lenses and implants to self-assembled nanomaterials. J Polym Sci, Part A: Polym Chem 2009;47(22):5929-46.

[21] Turbak AF, Snyder FW, Sandberg KR. Microfibrillated cellulose, a new cellulose product: properties, uses, and commercial potential. J Appl Polym Sci: Appl Polym Symp 1983;37:815-27.

[22] Lu J, Wang T, Drzal LT. Preparation and properties of microfibrillated cellulose polyvinyl alcohol composite materials. Comp Part A: Appl Sci Manufact 2008;39(5):738-46.

[23] Eichhorn SJ, Dufresne A, Aranguren M, Marcovich NE, Capadona JR, Rowan SJ, et al. Review: current international research into cellulose nanofibres and nanocomposites. J Mater Sci 2009;45(1):1-33.

[24] Hubbe MA. Are lignocellulosic resources too valuable to burn? BioResources 2008;3(2):295-6.

[25] Hubbe MA, Pawlak JJ, Koukoulas AA. Paper's appearance: a review. BioResources 2008;3(2):627-65.
[26] Zimmermann T, Pöhler E, Geiger T. Cellulose fibrils for polymer reinforcement. Adv Eng Mater 2004;6(9):754-61.

[27] Krupa I, Nedelcev T, Racko D, Lacik I. Mechanical properties of silica hydrogels prepared and aged at physiological conditions: testing in the compression mode. J Sol-Gel Sci Technol 2010;53(1):107-14.

[28] Pioletti DP, Rakotomanana LR. Non-linear viscoelastic laws for soft biological tissues. Eur J Mech, A/Solids 2000;19(5):749-59.

[29] Goto K, Shinzato S, Fujibayashi S, Tamura J, Kawanabe K, Hasegawa S, et al. The biocompatibility and osteoconductivity of a cement containing $\hat{\mathrm{I}}^{2}$-TCP for use in vertebroplasty. J Biomed Mater Res - Part A 2006;78(3):629-37.

[30] Hennink WE, van Nostrum CF. Novel crosslinking methods to design hydrogels. Adv Drug Deliv Rev 2002;54(1):13-36.

[31] Cavalieri F, Miano F, D’Antona P, Paradossi G. Study of gelling behavior of poly(vinyl alcohol)-methacrylate for potential utilizations in tissue replacement and drug delivery. Biomacromolecules 2004;5(6):2439-46.

[32] van Dijk-Wolthuis WNE, Franssen O, Talsma H, Van Steenbergen MJ, Kettenesvan den Bosch JJ, Hennink WE. Synthesis, characterization, and polymerization of glycidyl methacrylate derivatized dextran. Macromolecules 1995;28:6317-22.

[33] Liu Y, Chan-Park MB. Hydrogel based on interpenetrating polymer networks of dextran and gelatin for vascular tissue engineering. Biomaterials 2009;30(2):196-207.

[34] Fleury G, Schlatter G, Brochon C, Hadziioannou G. From high molecular weight precursor polyrotaxanes to supramolecular sliding networks. The 'sliding gels'. Polymer 2005;46(19 special issue):8494-501.

[35] Carl A, Ledet E, Yuan H, Sharan A. New developments in nucleus pulposus replacement technology. Spine J 2004;4(6 Suppl.):325S-9S.

[36] Lin-Gibson S, Jones RL, Washburn NR, Horkay F. Structure-property relationships of photopolymerizable poly(ethylene glycol) dimethacrylate hydrogels. Macromolecules 2005;38(7):2897-902.

[37] Gonen-Wadmany M, Oss-Ronen L, Seliktar D. Protein-polymer conjugates for forming photopolymerizable biomimetic hydrogels for tissue engineering. Biomaterials 2007;28(26):3876-86.

[38] Lee JH, Bucknall DG. Swelling behavior and network structure of hydrogels synthesized using controlled UV-initiated free radical polymerization. J Polym Sci, Part B: Polym Phys 2008;46(14):1450-62.

[39] Prasitsilp M, Siriwittayakorn T, Molloy R, Suebsanit N, Siriwittayakorn P, Veeranondha S. Cytotoxicity study of homopolymers and copolymers of 2hydroxyethyl methacrylate and some alkyl acrylates for potential use as temporary skin substitutes. J Mater Sci Mater Med 2003;14(7):595-600.

[40] van de Wetering P, Schuurmans-Nieuwenbroek NME, van Steenbergen MJ, Crommelin DJA, Hennink WE. Copolymers of 2-(dimethylamino)ethyl methacrylate with ethoxytriethylene glycol methacrylate or N-vinylpyrrolidone as gene transfer agents. J Control Release 2000;64(1-3):193-203.

[41] Furukawa H, Horie K, Nozaki R, Okada M. Swelling-induced modulation of static and dynamic fluctuations in polyacrylamide gels observed by scanning microscopic light scattering. Phys Rev E - Stat Nonlin Soft Matter Phys 2003;68(31):314061-3140614.

[42] Tanaka Y, Gong JP, Osada Y. Novel hydrogels with excellent mechanical performance. Progr Polym Sci (Oxford) 2005;30(1):1-9.

[43] Svensson A, Nicklasson E, Harrah T, Panilaitis B, Kaplan DL, Brittberg M, et al. Bacterial cellulose as a potential scaffold for tissue engineering of cartilage. Biomaterials 2005;26(4):419-31. 